\title{
SARS-CoV-2 Translocate from Nasopharyngeal to Bronchoalveolar Site: A Case Presentation
}

\author{
Filippo Luciani ${ }^{1,+}$, Erika Cione ${ }^{2, *+}+\mathbb{D}$, Maria Cristina Caroleo ${ }^{2}$, Manuela Colosimo ${ }^{3}$, \\ Alfredo Zanolini ${ }^{4}$, Antonio Barca ${ }^{4}$, Stefano Cosimo ${ }^{5}$, Pino Pasqua ${ }^{5}$ and Luca Gallelli ${ }^{6, *},+$ (D) \\ 1 Infectious Diseases Unit of Annunziata Hospital, 87100 Cosenza, Italy; filippoluciani@gmail.com \\ 2 Department of Pharmacy and Health and Nutritional Sciences-Department of Excellence 2018-2020, \\ University of Calabria, 87036 Rende (CS), Italy; mariacristinacaroleo@virgilio.it \\ 3 Department of Microbiology and Virology, Pugliese Ciaccio Hospital, 88100 Catanzaro, Italy; \\ lgallelli73@gmail.com \\ 4 Intensive Care Unit of Annunziata Hospital, 87100 Cosenza, Italy; alfredozanolini@gmail.com (A.Z.); \\ barcaantonio@hotmail.it (A.B.) \\ 5 Radiology Unit of Annunziata Hospital, 87100 Cosenza, Italy; stefanocosimo1978@libero.it (S.C.); \\ p.pasqua@virgilio.it (P.P.) \\ 6 Department of Health Science, University of Catanzaro and Operative Unit of Clinical Pharmacology and \\ Pharmacovigilance, Mater Domini Hospital, 88100 Catanzaro, Italy \\ * Correspondence: erika.cione@unical.it (E.C.); gallelli@unicz.it (L.G.); \\ Tel.: +39-0984493193 (E.C.); +39-0961712322 (L.G.) \\ + These authors contributed equally to this work.
}

Received: 22 July 2020; Accepted: 25 August 2020; Published: 26 August 2020

\begin{abstract}
The nasopharyngeal swab is commonly used for the diagnosis of SARS-CoV-2 infection. Since the swab is performed in this site, of course, it cannot detect the presence of the virus in other tissue districts such as the lung, brain, or bowel. In the present case report, the nasopharyngeal swab was negative twice. From this, the patient discontinued antiviral therapy. Nasopharyngeal swabs were maintained negative until five days later, when we recorded a severe impairment of the patient's clinical condition. At this time, the bronchoalveolar lavage was positive for SARS-CoV-2. The purpose of the case herein described is to suggest paying attention to the nasopharyngeal swab result. A negative detection in nasopharyngeal swab could not be indicative of COVID-19 recovery.
\end{abstract}

Keywords: SARS-CoV-2; infection; diagnosis

\section{Introduction}

The severe acute respiratory syndrome coronavirus 2 (SARS-CoV-2) infection causes the COVID-19 disease-acute and highly lethal pneumonia with clinical symptoms similar to those reported for other coronaviruses [1]. Drug therapy is not specific yet [2,3], and it should focus on early recognition of suspect cases [4]. The detection of viral nucleic acid through reverse transcription PCR (RT-PCR) represents the gold standard for the etiological diagnosis of COVID-19 [5]. However, some authors documented that the sensitivity of nasopharyngeal and oral swab RT-PCR assays for SARS-CoV-2 is very low, about 56\% and 83\% [6,7]. In particular, PCR cycles number are not standard for each type of test varying from 50 in "routine" to 40 in "emergency" [8,9].

In this manuscript, we are reporting a patient that for a negative nasopharyngeal swab RT-PCR discontinued antiviral therapy (AVT) with severe impairment of clinical condition. At this time, the bronchoalveolar lavage (BAL) was positive for COVID-19. 


\section{Case Presentation Section}

A 70-year old man with a history of heart transplantation (in 1996, taking everolimus and cyclosporine) and chronic renal failure (dialyzed) came to our observation on 13 March 2020. He traveled from Lombardy to Calabria 10 days before the presentation. He reported that, due to the lockdown related to COVID-19, he had not had dialysis since the end of February 2020. In agreement with Italian prevention for COVID-19, at the admission of the patient for performing dialysis, the nasopharyngeal swab was executed. The real-time reverse transcription-polymerase chain reaction (RT-PCR) revealed a SARS-CoV-2 infection. He was admitted to the infectious disease unit (IDU). He was asymptomatic since body temperature was $36^{\circ} \mathrm{C}$, heart frequency was $70 \mathrm{~b} / \mathrm{min}$, blood pressure was $140 / 90 \mathrm{~mm} / \mathrm{Hg}$. Instead, routine high-resolution computer tomography (HR-CT) documented some patchy ground-glass opacities in bilateral lung apices (see Figure 1A-C).
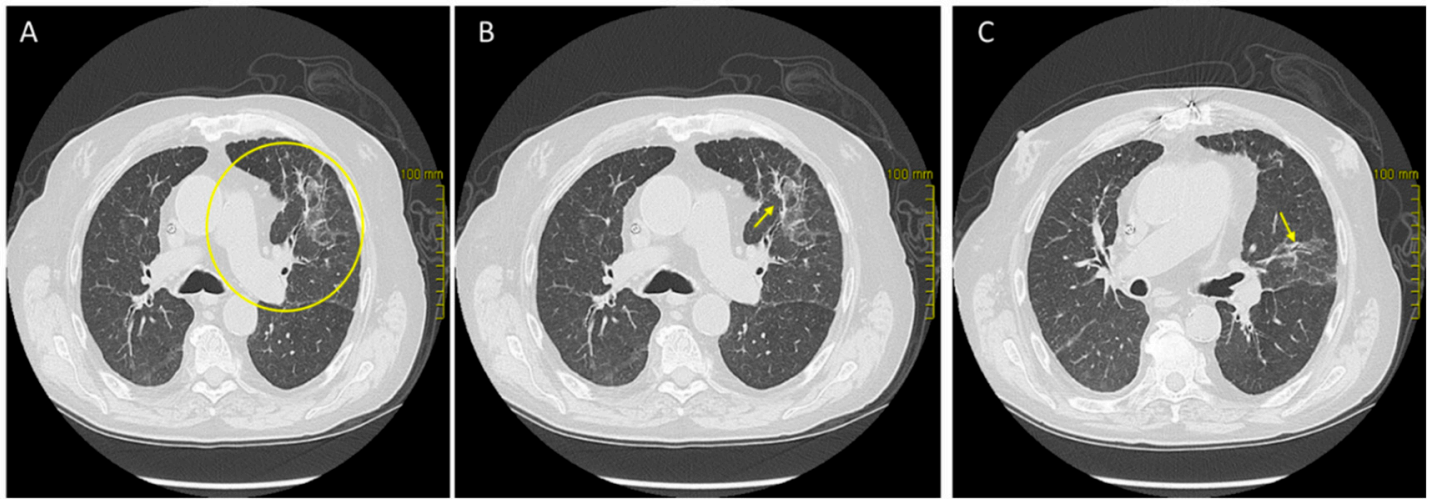

Figure 1. High-resolution computer tomography (HR-CT): (A) Thickening of the interlobular septa. (B) Patchy ground-glass opacity. (C) Lingula ground glass opacity.

Biochemical parameters revealed an increase in $\mathrm{C}$ reactive protein $(\mathrm{CRP}, 71.9 \mathrm{mg} / \mathrm{L}$; normal range $<6 \mathrm{mg} / \mathrm{L}$ ) and creatinine $(10.5 \mathrm{mg} / \mathrm{dL}$; normal range $0.55-1.18 \mathrm{mg} / \mathrm{dL}$ ) (see Table 1 ). Therefore, he was admitted to the infectious disease unit (IDU) and started both dialysis and antiviral treatment (hydroxychloroquine $200 \mathrm{mg} /$ day, darunavir $800 \mathrm{mg} /$ day, and ritonavir $100 \mathrm{mg} /$ day) with an initial improvement of the bio-parameters (see Table 1). We did not detect impairment in clinical conditions up to 29 March 2020, when clinical evaluation documented a severe respiratory failure (oxygen saturation 94\%; pH 7.04) with a severe decrease in blood pressure $(50 / 40 \mathrm{~mm} / \mathrm{Hg})$ and normal body temperature $\left(36^{\circ} \mathrm{C}\right)$. The biochemical parameters documented an increase in plasma IL-6 $(580 \mathrm{pg} / \mathrm{mL})$ levels with normal values of Vitamin D $(26 \mathrm{ng} / \mathrm{mL})$. Anesthesiology consultant diagnosed a metabolic acidosis in a dialytic patient with chronic renal failure and heart transplantation. The interstitial pneumonitis was related to COVID-19. Therefore, treatment with sodium bicarbonate (100 mL), dopamine $(10 \mathrm{mcg} / \mathrm{kg} / \mathrm{min} ; 10 \mathrm{~mL} / \mathrm{h})$, and oxygen was started. Due to the critical condition of the patient nasopharyngeal swab for SARS-CoV-2 detection was performed in an emergency situation on 30 March 2020, and the day after, following the BGI's Real-Time Fluorescent RT-PCR Kit for SARS-CoV-2 Assay, both were negative [9]. Therefore, antiviral therapy was discontinued.

Due to the impairment of his clinical conditions (oxygen saturation 97\% with oxygen therapy, blood pressure 120/70 with noradrenaline treatment $2 \mathrm{mg} / \mathrm{mL}$ and enoxaparin $4000 \mathrm{IU}$ ) on 2 April 2020, the patient was transferred to the intensive cardiac care unit (ICCU), where echocardiogram documented left ventricular hypokinesia (ejection faction 35\%) without cough and fever. Three days later (5 April 2020), for the severe impairment of clinical condition (coma Glasgow score 3), the patient was moved from ICCU to the intensive care unit (ICU), where the patient was intubated for mechanical ventilation. Here, the consultant in infectious disease, disposed test for SARS-CoV-2 infection again from nasopharyngeal swab and BAL, finding this latter positive (see Figure 2). Patient's death occurred due to severe blood hypotension unresponsive to noradrenaline and dopamine. We have received consent from the patient. 
Table 1. Clinical parameters, clinical biochemistry and pharmacology profile recorded during the hospitalization (13 March 2020: admission; 5 April 2020: exitus).

\begin{tabular}{|c|c|c|c|c|c|c|}
\hline Bio-Parameters & $\begin{array}{l}\text { 13rd } \\
\text { March }\end{array}$ & $\begin{array}{c}\text { 21st } \\
\text { March }\end{array}$ & $\begin{array}{l}\text { 25th } \\
\text { March }\end{array}$ & $\begin{array}{l}\text { 3rd } \\
\text { April }\end{array}$ & $\begin{array}{l}\text { 5th } \\
\text { April }\end{array}$ & Normal Range \\
\hline Fever & 36 & 36.2 & 36 & 36 & 36.1 & 0-180 IU/L \\
\hline Blood pressure & $120 / 80$ & $120 / 80$ & $140 / 90$ & $88 / 53$ & $80 / 50$ & $\begin{aligned} & <140 \text { systolic and } \\
< & 90 \text { diastolic } \mathrm{mm} / \mathrm{Hg}\end{aligned}$ \\
\hline Oxygen saturation & $97 \%$ & $95 \%$ & $94 \%$ & $\begin{array}{l}96 \% \text { in oxygen } \\
\text { therapy }\end{array}$ & $\begin{array}{l}96 \% \text { in oxygen } \\
\text { therapy }\end{array}$ & $>95 \%$ \\
\hline C-reactive protein & 71.9 & 6.28 & 19.7 & 28.4 & 30 & $<6 \mathrm{mg} / \mathrm{L}$ \\
\hline Sodium & 130 & 130 & 138 & 142 & 147 & $135-145 \mathrm{mM} / \mathrm{L}$ \\
\hline Potassium & 4.2 & 7.4 & 5.1 & 5.3 & 6.3 & $3.6-5.1 \mathrm{mM} / \mathrm{L}$ \\
\hline Creatinine & 10.5 & 8.4 & 7.9 & 8.85 & 7.43 & $0.55-1.18 \mathrm{mg} / \mathrm{dL}$ \\
\hline Blood glucose & 85 & 88 & 90 & 643 & 258 & 74-106 mg/dL \\
\hline $\begin{array}{l}\text { Alanine amino } \\
\text { transferase }\end{array}$ & 6 & 6 & 10 & 10 & 33 & 5-50 IU/L \\
\hline $\begin{array}{l}\text { Aspartate amino } \\
\text { transferase }\end{array}$ & 6 & 7 & 11 & 15 & 71 & 5-50 IU/L \\
\hline $\begin{array}{c}\text { Lactate } \\
\text { dehydrogenase }\end{array}$ & 180 & 200 & 217 & 215 & 230 & 50-248 IU/L \\
\hline Vitamin D & 26 & 26 & 26 & - & - & $20-60 \mathrm{ng} / \mathrm{mL}$ \\
\hline Interleukin-6 & 12 & 37.3 & 529.9 & 134.1 & - & $<6 \mathrm{pg} / \mathrm{mL}$ \\
\hline Cyclosporine & 650 & 579 & - & - & - & $200-350 \mathrm{ng} / \mathrm{mL}$ \\
\hline Everolimus & 50 & 42 & - & - & - & $3-8 \mathrm{ng} / \mathrm{mL}$ \\
\hline
\end{tabular}

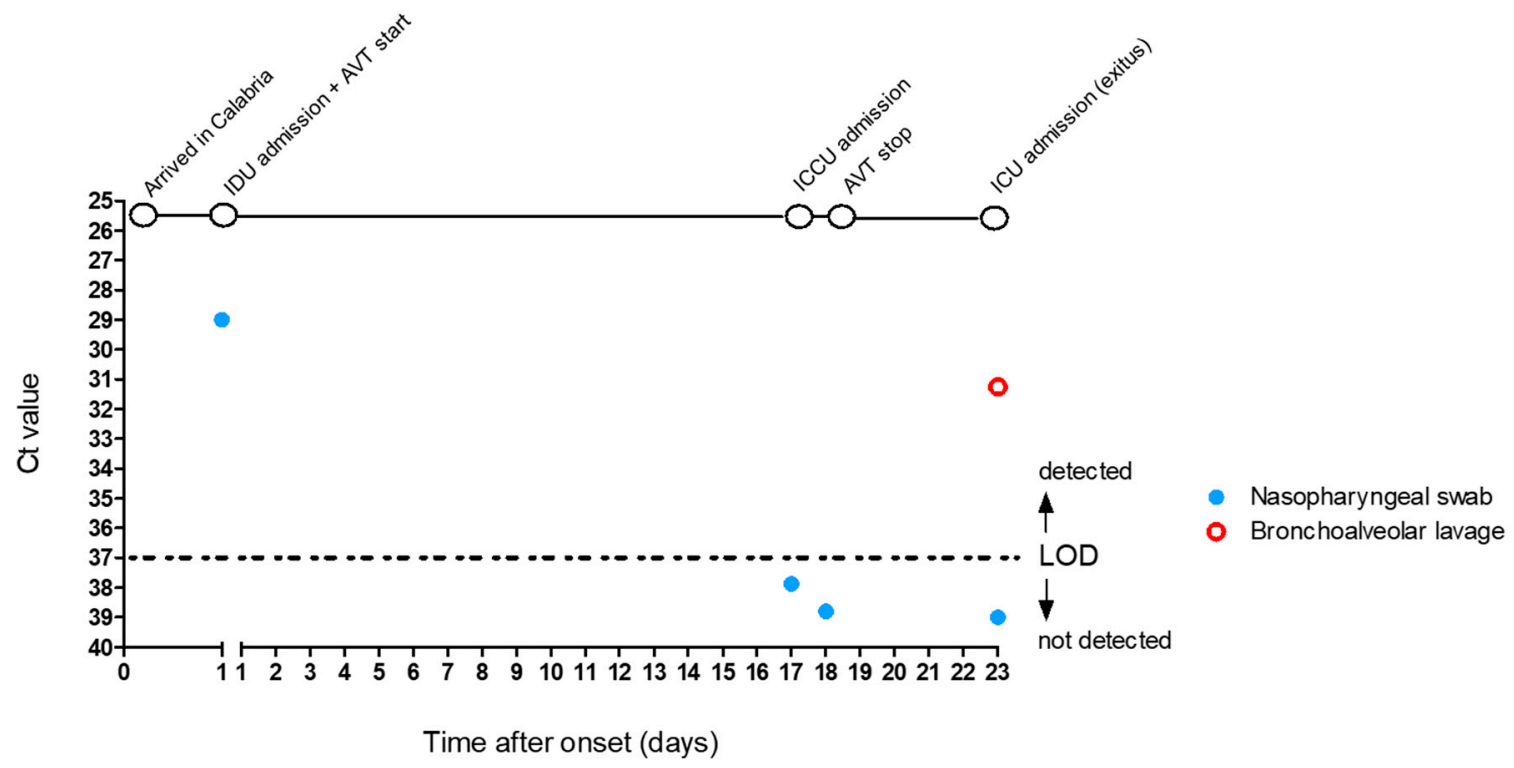

Figure 2. Reverse transcription PCR (RT-PCR): in blue, nasopharyngeal swab. In red, bronchoalveolar lavage. Cycle threshold value (Ct value) $37 \mathrm{Ct}$ is the limit of detection (LOD). Other abbreviations: infectious disease unit (IDU); intensive cardiac care unit (ICCU); antiviral therapy (AVT); intensive care unit (ICU). 


\section{Discussion}

The nasopharyngeal swab is commonly used for the diagnosis of SARS-CoV-2 infection [10]. SARS-CoV-2 was also monitored in other body fluids, but never in BAL until now [11]. In the present case report, the nasopharyngeal swab was negative twice. This convinced the clinicians to discontinue the AVT. The worsening of clinical conditions and the searching of SARS-CoV-2 nucleic acid into BAL confirmed its presence in this site. The importance to use this is a minimally invasive procedure useful for the diagnosis of both infections and neoplastic lesions [12,13]. We suggest to evaluate with attention when is mandatory to do the BAL together with the nasopharyngeal swab it was negative in our case-in order to avoid the missed diagnosis with the discontinuation of the pharmacological therapy. Results from RT-PCR are challenging since so many different tests are available for SARS-CoV-2 nucleic acid detection and global/universal standardization is lacking [14].

\section{Conclusions}

SARS-CoV-2 nucleic acid detection is actually performed only as a nasopharyngeal swab. Herein we evidenced the localization of the virus into the BAL. From our results, we speculate that the macrophage from bronchoalveolar tissue district could be a SARS-CoV-2 reservoir.

Author Contributions: F.L., A.Z., A.B., P.P. and S.C. have full access to all of the data in the study and take responsibility for the integrity of the data and the accuracy of the data analysis. Study concept and design: F.L., and E.C. Acquisition of data: F.L., M.C.C., L.G. Analysis and interpretation of data: E.C., F.L. and M.C. Drafting of the manuscript: E.C. and L.G. All authors have read and agreed to the published version of the manuscript.

Funding: We did not receive funding for this study.

Conflicts of Interest: The authors declare no conflict of interest.

\section{References}

1. Pal, M.; Berhanu, G.; Desalegn, C.; Kandi, V. Severe Acute Respiratory Syndrome Coronavirus-2 (SARS-CoV-2): An Update. Cureus 2020, 12, e7423. [CrossRef]

2. Gallelli, L.; Zhang, L.; Wang, T.; Fu, F. Severe Acute Lung Injury Related to COVID-19 Infection: A Review and the Possible Role for Escin. J. Clin. Pharmacol. 2020, 60, 815-825. [CrossRef]

3. Stebbing, J.; Phelan, A.; Griffin, I.; Tucker, C.; Oechsle, O.; Smith, D.; Richardson, P. COVID-19: Combining antiviral and anti-inflammatory treatments. Lancet Infect. Dis. 2020, 20, 400-402. [CrossRef]

4. Laboratory Testing for Coronavirus Disease (COVID-19) in Suspected Human Cases. Available online: https://apps.who.int/iris/handle/10665/331329 (accessed on 2 March 2020).

5. Centers for Disease Control and Prevention (CDC). Coronavirus Disease 2019 (COVID-19) 2020. Available online: https://www.cdc.gov/coronavirus/2019-ncov/index.html (accessed on 2 March 2020).

6. Yang, Y.; Yang, M.; Shen, C.; Wang, F.; Yuan, J.; Li, J. Evaluating the accuracy of different respiratory specimens in the laboratory diagnosis and monitoring the viral shedding of 2019-nCoV infections. medRxiv 2020. [CrossRef]

7. Wang, W.; Xu, Y.; Gao, R.; Lu, R.; Han, K.; Wu, G.; Tan, W. Detection of SARS-CoV-2 in Different Types of Clinical Specimens. JAMA 2020, 323, 1843-1844. [CrossRef] [PubMed]

8. Marando, M.; Tamburello, A.; Gianella, P. False-Negative Nasopharyngeal Swab RT-PCR Assays in Typical COVID-19: Role of Ultra-low-dose Chest CT and Bronchoscopy in Diagnosis. EJCRIM 2020, 7. [CrossRef]

9. Real-Time Fluorescent RT-PCR Kit for Detecting SARS-CoV-2. Available online: https://www.fda.gov/media/ 136472/download (accessed on 2 March 2020).

10. Zitek, T. The Appropriate Use of Testing for COVID-19. West. J. Emerg. Med. 2020, 21, 470-472. [CrossRef]

11. Thevarajan, I.; Nguyen, T.H.O.; Koutsakos, M.; Druce, J.; Caly, L.; Van De Sandt, C.E.; Jia, X.; Nicholson, S.; Catton, M.; Cowie, B.; et al. Breadth of concomitant immune responses prior to patient recovery: A case report of non-severe COVID-19. Nat. Med. 2020, 26, 453-455. [CrossRef]

12. Radha, S.; Afroz, T.; Prasad, S.; Ravindra, N. Diagnostic utility of bronchoalveolar lavage. J. Cytol. 2014, 31 , 136-138. [CrossRef] 
13. Meyer, K.C.; Raghu, G. Bronchoalveolar lavage for the evaluation of interstitial lung disease: Is it clinically useful? Eur. Respir. J. 2011, 38, 761-769. [CrossRef]

14. Corman, V.M.; Landt, O.; Kaiser, M.; Molenkamp, R.; Meijer, A.; Chu, D.K.; Bleicker, T.; Brünink, S.; Schneider, J.; Schmidt, M.L.; et al. Detection of 2019 novel coronavirus (2019-nCoV) by real-time RT-PCR. Eurosurveillance 2020, 25, 2000045. [CrossRef]

(C) 2020 by the authors. Licensee MDPI, Basel, Switzerland. This article is an open access article distributed under the terms and conditions of the Creative Commons Attribution (CC BY) license (http://creativecommons.org/licenses/by/4.0/). 